I Université de Lille I, Faculté des Sciences Economiques et Sociales, Lille, France licia.valladares@univ-liller.fr

II Casa de Oswaldo Cruz (COC), Departamento de Arquivo e Documentação, Fiocruz, Rio de Janeiro, RJ, Brasil aline.lacerda@fiocruz.br

III Casa de Oswaldo Cruz (COC), Departamento de Arquivo Licia do Prado Valladares' nota técnica e Documentação, Fiocruz, Rio de Janeiro, RJ, Brasil ana.girao@fiocruz.br Aline Lopes de Lacerda" Ana Luce Girão'II

\title{
ANTHONY LEEDS: O ESQUECIMENTO E A MEMÓRIA
}

\begin{abstract}
A doação do arquivo pessoal do antropólogo norte-americano Anthony Leeds (I925-I989) à Casa de Oswaldo Cruz e sua organização, com apoio da Faperj, permitiram que se tornassem acessíveis fontes sobre a história da habitação popular na América Latina e da pesquisa antropológica e sociológica correspondente. Doado por sua viúva e colaboradora em inúmeros trabalhos, a cientista política Elizabeth Leeds, o acervo reúne material valioso para os estudos sobre a constituição/transformação das favelas; os movimentos sociais, as políticas públicas e a produção de conhecimento sobre essa forma de moradia. Com o seminário, pretendemos tornar públicos os primeiros resultados do trabalho realizado em colaboração com o Urbandata-Iesp/Uerj, promover o debate e estimular linhas e projetos de pesquisa sobre a história da favela e da sociologia do Brasil urbano.
\end{abstract}

Faço minhas essas palavras de Nísia Trindade Lima proferidas na ocasião do seminário "O Rio que se queria negar: as favelas do Rio de Janeiro no acervo de Anthony Leeds na década de I960". E é na qualidade de coordenadora emérita do Urbandata-Brasil que estou aqui para dar meu testemunho sobre a importância de Anthony Leeds para a sociologia e para a antropologia urbanas brasileiras. Eu era jovem e estudava a favela da Rocinha nos idos de I967 quando conheci e convivi com Leeds. Aprendi muito com essa experiência e devo a ele várias das ideias que hoje defendo, bem como a apologia que venho fazendo da pesquisa comparativa.

Dos vários aspectos da recepção da obra de Leeds privilegiarei aqui seu esquecimento, e, desse modo, a importância de um arquivo que resgatará sua memória tem diretamente a ver com isso. Parto da constatação de que para as novas gerações, exceção feita aos historiadores dedicados à questão urbana, Anthony Leeds é um ilustre desconhecido. É o que verifico lendo obras recentes: só excepcionalmente artigos e livros em português o citam. É como se Leeds não tivesse deixado contribuição expressiva na história da pesquisa urbana no Brasil e no Rio de Janeiro e fizesse parte de um passado que não interessa res- 
suscitar. Gilberto Velho, ${ }^{2}$ que deveria participar deste evento (chegando mesmo a aceitar o convite que lhe foi feito), não está mais, infelizmente, entre nós para dar seu testemunho da importância de Leeds para o pensamento antropológico e a pesquisa em favelas. Legou-nos, entretanto, o artigo "Antropologia urbana: interdisciplinaridade e fronteiras do conhecimento", no qual discute a complexidade desse campo e a relevância de abordagens interdisciplinares, enfatizando o quanto elas estiveram presentes em sua carreira intelectual e suas relações com diferentes cientistas sociais, escritores e artistas. Nesse artigo, Velho destaca o papel de Anthony Leeds, então docente do Departamento de Antropologia da Universidade de Texas, como primeiro professor do curso de antropologia urbana no Museu Nacional, mediante o convênio, à época vigente, com a Fundação Ford. Observa que o perfil teórico de Anthony Leeds não era nada simples, mas que sua singularidade estava sobretudo na grande liderança e competência na abertura de frentes de trabalho de campo. Teria sido o interesse pela questão habitacional que mais os aproximou (Velho, 20II).

Vale a pena lembrar que Gilberto Velho foi aluno de Leeds no Museu Nacional (juntamente com Yvonne Maggie, ${ }^{3}$ Luiz Antonio Machado da Silva, ${ }^{4}$ Paul Silberstein, ${ }^{5}$ entre outros) e que foi desse curso que saiu a primeira versão do seu trabalho sobre Copacabana (depois transformado em tese e publicado sob o título A utopia urbana) (Velho, I973). Foi também Gilberto que teve a ideia de publicar em português, na série da Editora Zahar que então dirigia, os artigos de Anthony Leeds e Elizabeth Leeds, apresentados em vários congressos e até então só conhecidos de alguns. O livro é de 1978 e chama-se A sociologia do Brasil urbano. Só foi reeditado em $2015,{ }^{6}$ apesar de ser obra clássica no estudo das favelas.

Que razões, porém, poderiam explicar o "esquecimento" de Anthony Leeds? A primeira delas tem a ver com o fato de que Leeds era um acadêmico e não um homem vinculado a resultados que pudessem ser usados com finalidade política. Suas preocupações eram de natureza mais teórica. Quando esteve pela primeira vez no Brasil, nos anos I950, participou do projeto que ficou conhecido como Bahia-Columbia, dirigido por Charles Wagley,? Costa Pinto e Thales de Azevedo, ${ }^{8}$ então diretor da Fundação para o Desenvolvimento da Ciência no Estado da Bahia (Maio, I997; Wagley, Costa Pinto \& Azevedo, I950). Trabalhos de tese de estudantes de pós-graduação da Universidade de Columbia foram realizados a partir do projeto, como foi o caso de Leeds, que desenvolveu, sob orientação de Charles Wagley, a pesquisa da qual resultou sua tese de doutoramento sobre ciclos econômicos no Brasil e a produção de cacau na Bahia.

Mais tarde, ao retornar ao Brasil no início dos anos I960 como chefe do Programa de Desenvolvimento Urbano da União Pan-Americana, ${ }^{9}$ Leeds se interessou pela estrutura social brasileira, pelas relações entre as elites e as classes populares, pelas estruturas de poder e pelas diferentes formas de mobilidade social. Escreveu então o artigo "Brazilian careers and social structure" mente publicado em I964), que tornou seu nome conhecido no meio acadêmico 
dos Estados Unidos. O artigo é oriundo de sua tese de doutorado e tinha, portanto, caráter nitidamente acadêmico. Também foi nesse período que, no Rio de Janeiro, começou a se voltar para as favelas, iniciando pesquisa nessas localidades em I965. Um de seus principais interlocutores sobre o tema foi José Arthur Rios, ${ }^{\text {II }}$ na época diretor da Sociedade para Análise Gráfica e Mecanográfica Aplicada aos Complexos Sociais (Sagmacs), a quem, então, se dirigiam todos aqueles interessados no tema favela. Arthur Rios havia trabalhado com o padre Lebret $^{12}$ na primeira pesquisa empírica sobre as favelas do Rio - "Aspectos Humanos da Favela Carioca". ${ }^{13}$

Leeds, no entanto, não vai se interessar pelas favelas do Rio de Janeiro em si. Apesar de estudar Tuiuti e Jacarezinho, onde morou, buscou ampliar seu trabalho por meio de uma perspectiva comparativa, recorrendo ao diálogo acadêmico com colegas estudiosos de outros países latino-americanos, como John Turner, ${ }^{14}$ William Mangin ${ }^{15}$ e José Mattos Mar. ${ }^{16}$ Sua preocupação era propor generalizações e uma explicação global, sem se limitar a estudos de caso tomados isoladamente (ver Leeds, I969). Pretendia explicar o aparecimento, desenvolvimento e natureza dos squatter settlements ${ }^{17}$ por meio de variáveis primárias, secundárias e terciárias. As variáveis primárias compreendiam as sociedades de economia capitalista em que a terra e a habitação têm alto valor, o mercado de trabalho é dual e fatores sócio-político-administrativos também contam. Já as variáveis secundárias consistiam na história da cidade e de seu mercado de trabalho e de habitação, quadro institucional, políticas de habitação desenvolvidas etc. E as variáveis terciárias, por sua vez, diziam respeito aos aspectos específicos dos aglomerados (squatter settlements), tais como clima e topografia, localização no mercado de trabalho, idade, tamanho do aglomerado, economia interna, história das relações com órgãos públicos e privados, voto e comportamento eleitoral, religião e papel das iniciativas privadas (ainda não existiam as ONGs) etc. Anthony Leeds era antes de tudo um professor, que se interessava por pesquisa, por seus resultados e que tinha espírito crítico. Respeitava o trabalho acadêmico, tinha uma visão crítica dos fenômenos sociais e valorizava esse tipo de trabalho.

Leeds também teria sido esquecido pelas novas gerações por não tratar em seus escritos de problemas que hoje são contundentes, como a violência e a criminalidade urbanas. Violência urbana não foi tema que ele tenha explorado. Praticamente a violência e o tráfico não eram ainda importantes na época em que estudou favelas. Não eram ainda temas prioritários da sociologia urbana. Tornaram-se incontornáveis dos anos I980 em diante, quando pensar a favela passou a ser também pensar a violência que dela emana. Elizabeth Leeds, sua viúva, foi quem, anos após sua morte, veio a estudar a violência com ênfase em direitos humanos no Brasil e a reforma da polícia. Entre suas publicações sobre o tema, o artigo "Cocaína e poderes paralelos na periferia urbana brasileira. Ameaças à democratização em nível local”, hoje muito citado, foi 
recolhido em Um século de favela, organizado por Alba Zaluar \& Marcos Alvito (I998), e publicado originalmente em I996 na Latin American Research Review. ${ }^{18}$

Para os scholars americanos, o interesse atual no Brasil é o de estudar relações raciais e violência, quando não o feminismo. Quando os norte-americanos vêm atualmente estudar "favela" a utilizam como cenário e o fazem pela perspectiva da raça e da discriminação racial, como Donna Goldstein (2003) que, em seu livro etnográfico Laughter out of place, estudou uma favela da Zona Oeste; ou Robin Sheriff (200I) que, em Dreaming equality, estudou a favela Dona Marta.

Leeds não chegou a enfatizar a desigualdade racial existente entre a população residente. Na época não havia ainda a affirmative action tão propalada entre os americanos, o movimento feminista ainda não era relevante, e os moradores de favela eram de todas as cores e raças. Não chamaram sua atenção diferenças de raça e de cor entre os moradores de favelas. Não considerou a cor da pele variável analítica em suas pesquisas. Nessa época estava em voga antes o conceito de "cultura da pobreza", e é com a questão substantiva da pobreza e com esse conceito que ele dialoga (Leeds \& Leeds, I970), como vemos no artigo "O Brasil e o mito da ruralidade urbana: experiência urbana, trabalho e valores nas 'áreas invadidas' do Rio de Janeiro e de Lima", recolhido em A sociologia do Brasil urbano (Leeds \& Leeds, 20I5). ${ }^{\text {I9 }}$ Era, portanto, outro o paradigma adotado. Paul Silberstein, voluntário da paz que foi discípulo de Leeds, em artigo publicado no mesmo número de América Latina"o ("Favela living: personal solution to larger problems" ${ }^{21}$ ) critica Oscar Lewis ${ }^{22}$ por caracterizar os pobres como tendo um feeling de marginalidade, de impotência, de dependência e de inferioridade.

Também estava em voga na época a noção de marginalidade social, e Leeds vai de encontro a ela. Apoiando-se em W. Mangin, em seus estudos sobre as populações pobres da América Latina e do Brasil Leeds mostrou que, contrariamente às ideias expressas por Carolina Maria de Jesus (I960), ${ }^{23}$ autora de Quarto de despejo, havia heterogeneidade dentro das favelas. Os moradores estariam integrados via, por exemplo, o mercado de trabalho, e não marginalizados, como se dizia. A crítica a concepções correntes nas décadas de i950 e ig6o sobre urbanismo e urbanização (a urbanização não causava necessariamente a marginalidade) parece ter-se configurado como uma das preocupações centrais da sua agenda de pesquisas. Leeds, entretanto, apesar de ter publicado artigos resultantes de suas pesquisas, ${ }^{24}$ não chegou a escrever um livro sobre as favelas em inglês. Coube a Janice Perlman publicar o primeiro livro em inglês, de grande repercussão: The myth of marginality. ${ }^{25}$

Por fim, entre as possíveis razões para seu esquecimento, cabe notar que Leeds critica o conceito de comunidade, que fez grande fortuna nas ciências sociais brasileiras e tinha por base a formulação clássica de Robert Redfield. ${ }^{26}$ Como se sabe, nessa acepção seriam características da comunidade: a união entre os membros, a predominância de relações face a face, o predomínio das relações de troca em lugar de uma economia capitalista com base no dinheiro, 
a importância da vizinhança etc. Ao contrário, segundo Leeds, favela é uma localidade. Essa categoria parte de uma perspectiva relacional do lugar com a cidade, não adotando a perspectiva isolacionista do conceito de comunidade. Para ele, as favelas enquanto localidades inserem-se na cidade, constituindo-se por relações urbanas, integrando-se ao mercado e à economia capitalistas. Não há nada demais em se falar em "favela". Favela é simplesmente um qualificativo de lugar e uma forma de moradia, constituindo-se em uma resposta aos problemas enfrentados pelos trabalhadores de baixa renda.

Atualmente é politicamente correto referir-se às favelas como comunidades. Esquece-se de que as assistentes sociais da época de Getúlio usavam a palavra comunidade, que os Voluntários da Paz evocavam e pregavam o desenvolvimento comunitário. Hoje os bandidos ligados ao tráfico, os presidentes das associações de moradores, os mais jovens moradores, alguns pesquisadores, alguns membros de ONGs, os representantes dos órgãos públicos que atuam em favelas usam, com frequência, a palavra comunidade. Esse termo deixa de lado a crítica feita por Anthony Leeds de que a concepção de comunidade não dava conta do aspecto relacional dessas localidades com as outras, tampouco com a cidade na qual se inseriam, não constituindo enclaves ou quistos separados da cidade. ${ }^{27}$

Seja como for, Anthony Leeds é importante para as ciências sociais brasileiras em vários sentidos. Sem querer ser exaustiva, lembro: primeiro, teve papel fundamental na formação de cientistas sociais no Museu Nacional, onde, em I969, o mestrado apenas começando, foi professor convidado por Roberto Cardoso de Oliveira. ${ }^{28}$ Segundo, insistiu na pesquisa comparativa numa época em que as comparações não tinham a importância que têm atualmente. Terceiro, perguntou-se sobre as origens dos squatter settlements, fenômeno urbano por ele observado em diversos países da América Latina, embora com nomes diferentes em cada país - tugúrios, barriadas, calejones, favelas etc. -, insistindo que seu único traço comum era a origem: não ser proprietário (illegal tenure). Para Leeds, a posse, o uso ou a apropriação ilegal era o ponto comum aos vários assentamentos não controlados. Por fim, enfatizou a grande heterogeneidade no universo das favelas, mostrando, por exemplo, que os settlements variam de acordo com sua formação, causas e natureza (cada um tem uma história), tamanho, recursos disponíveis, estrutura física e social. Variam também quanto à população que abrigam.

Para finalizar me pergunto sobre o impacto de Leeds sobre mim mesma. Foi nas reuniões em sua casa que conheci muitos dos americanos que na época estavam no Rio: Paul Silberstein (Peace Corps), Lawrence Salmen, ${ }^{29}$ Janice Perlman, entre outros (alguns faziam o PhD tendo como "campo" as favelas do Rio de Janeiro). Foi Leeds que me introduziu na perspectiva latino-americana. Foi por seu intermédio que ouvi pela primeira vez falar em John Turner (I966), que era seu amigo, e que tive acesso ao artigo "Uncontrolled urban settlements: problems and policies", hoje um clássico da literatura que aborda as favelas sem as 
estigmatizar ou caracterizar de modo simplificado como problema social. Foi também por seu intermédio que li "Latin American squatter settlements: a problem and a solution", de William Mangin (1967), artigo seminal dos anos I960I970, contrário à teoria da marginalidade social.

Anthony Leeds me ensinou, sobretudo, duas coisas. Primeiro, a importância do trabalho em equipe e o sentido da troca. Em pesquisa o contato entre pesquisadores é fundamental. Muito se aprende com os outros, na troca de experiência. Agia como Robert Park ${ }^{30}$ em Chicago nos anos I920, que fazia reuniões com seus alunos nas quais cada um relatava o que estava acontecendo no "campo". Com isso, cada aluno aprendia com a experiência do outro. Leeds fazia algo muito semelhante, substituindo, porém, os diversos bairros de Chicago pelas diferentes favelas e suas especificidades. Segundo, me ensinou que as favelas são todas diferentes entre si e que a forma como se dá a ocupação inicial é essencial em suas configurações e trajetórias. Seu artigo "The significant variables determining the character of squatter settlements"(Leeds, I969) foi fundamental na minha formação ao chamar a atenção para a necessidade de comparar favela com periferia, problematizando, assim, a noção da favela como "caso único", de modo a considerar não apenas a diversidade das favelas em relação a tamanho, população, política interna, dinâmica econômica etc., mas também as outras formas de habitação de baixa renda, tais como os cortiços, cabeças de porco, casas de cômodos.

A influência de Anthony Leeds na obra de pesquisadores que contribuíram para a constituição dos campos da sociologia e da antropologia urbanas no Brasil e a atualidade de sua perspectiva ao propor uma abordagem atenta à heterogeneidade e à inserção das favelas na vida da cidade configuram aspectos centrais que busquei enfatizar neste texto. Com ele pretendo também incentivar novas pesquisas que possam agora recorrer a seu acervo para discutir em perspectiva histórica as favelas e os estudos urbanos realizados no país.

\section{NOTA TÉCNICA}

\section{A trajetória do arquivo}

Os documentos que compõem o Arquivo Pessoal do antropólogo norte-americano Anthony Leeds (I925-1989) foram doados à Casa de Oswaldo Cruz/Fiocruz em 2007 por sua viúva, a cientista política Elizabeth Leeds. Até chegarem ao Rio de Janeiro, no mesmo ano, eles venceram um longo percurso, desde a farmhouse do casal na localidade de Randolph, no estado de Vermont, onde ficaram guardados após o falecimento de Anthony Leeds, em I989. Um dos primeiros contatos de Elizabeth Leeds para efetivar a doação do acervo foi por um e-mail que trazia anexado o inventário provisório das I 2 caixas. Segundo a doadora, as caixas continham registros de algumas das pesquisas empreendidas pelo casal no Brasil e na América Latina, relativas ao fenômeno das favelas, vilas, tugúrios e barriadas, às políticas habitacionais da região nas décadas de I960 a I980; e à atuação dos 
movimentos sociais e dos órgãos governamentais e não governamentais nas favelas e em outras localidades carentes do Brasil. Naquela mensagem, Elizabeth Leeds avisava que era necessário aguardar o verão para que a documentação, até então submetida a temperaturas que ao longo do ano variavam entre $20^{\circ}$ e $80^{\circ}$ Fahrenheit (ou $26^{\circ}$ e $-6^{\circ}$ Celsius), pudesse ser enviada para o Brasil.

Outra parcela de documentos do arquivo Leeds já havia sido doada por Elizabeth Leeds para o National Anthropological Archives do Smithsonian Institute. Conforme a página eletrônica dessa instituição, ${ }^{31}$ lá se encontram materiais biográficos; cartas enviadas e recebidas; calendários; materiais relacionados a suas pesquisas sobre a zona do cacau no estado da Bahia, os índios Yaruro da Venezuela, antropologia urbana e escravidão brasileira; documentos do período de formação acadêmica do titular; críticas; poemas; notas diversas; e documentos sobre sua atividade docente em universidades norte-americanas, além de materiais referentes a pesquisas realizadas na Europa.

A primeira remessa do arquivo doado à Casa de Oswaldo Cruz foi organizada no âmbito da pesquisa "História das favelas e da sociologia do Brasil urbano: contribuições ao seu estudo a partir da trajetória de Anthony Leeds". Coordenada por Nísia Trindade Lima, e com financiamento da Faperj, essa pesquisa contou ainda com a participação de Licia Valladares (Universidade de Lille/Urbandata/Iuperj), Luiz Antonio Machado (Urbandata/Iuperj), Tania Fernandes (Casa de Oswaldo Cruz) e Claudia Trindade (Casa de Oswaldo Cruz). Coube a nós, do Departamento de Arquivo da Casa de Oswaldo Cruz, coordenar a organização do acervo documental.

Em 2009 iniciamos o tratamento técnico com um diagnóstico sobre as condições de conservação dos papéis e em seguida com a identificação dos documentos. Nessa fase pudemos observar que parte considerável da documentação já havia recebido algum tipo de organização pois se encontrava agrupada em pequenos maços de documentos dentro de pastas contendo numeração e notas manuscritas. Durante toda a fase de identificação foi mantida a organização e a ordenação original visando preservar a lógica de acumulação dada pelo titular e pela doadora. Essa marca foi, na medida do possível, conservada na organização final que o arquivo recebeu. Em meio à documentação sobre favelas, por exemplo, havia várias pastas com nomes de favelas ou de localidades nas quais se encontravam anotações manuscritas, relatórios de campo e entrevistas feitas pelo próprio Leeds, bem como por integrantes de sua equipe de pesquisa e do Peace Corps Volunteers, além de correspondência com alguns moradores de favelas. Foram encontradas algumas pastas com o nome da favela assinalado, mas sem documentos. No entanto, são registros de um método de trabalho, de interesses projetados para o futuro, e são também lacunas que podem ser preenchidas com outras fontes de informação. E, ainda, são marcas que sinalizam a quem lida com a tarefa de organizar o arquivo, os processos intencionais de escolha e seleção do produtor. ${ }^{32}$ Como nos ensina Heymann (20I 2: I79), diferen- 
temente do processo de acumulação dos arquivos institucionais, os arquivos pessoais "trazem a marca de um processo de acumulação pautado por subjetividades individuais, expressas na seleção dos documentos a ser preservados, bem como em sucessivas avaliações, descartes e ordenamentos a que os conjuntos podem ser submetidos".

Entre as principais tipologias encontradas há um volume considerável de recortes de jornal e de outros materiais impressos de divulgação, relatórios, anotações manuscritas, entrevistas, mapas, plantas topográficas, correspondência e atas de reunião, além de pôsteres, cartas e plataformas políticas apresentadas em campanhas para eleições em diversas associações de moradores, entre outros documentos. O conjunto que se encontrava aparentemente sem organização, "solto" nas caixas, continha livros, artigos, separatas, dissertações e teses relativos ao período de docência no Museu Nacional, além de um número considerável de trabalhos apresentados nas reuniões anuais da Associação Nacional de Pós-Graduação em Ciências Sociais (Anpocs). No âmbito desse evento, boa parte dos textos foi apresentada nos grupos de trabalho sobre movimentos sociais urbanos, políticas de habitação e outros temas relacionados à antropologia urbana e às favelas. Entre os trabalhos acadêmicos encontram-se alguns orientados por Leeds e outros nos quais sua obra aparece como referência bibliográfica.

Em 20I I houve uma segunda remessa de I 2 documentos manuscritos e datilografados, novamente organizados por Elizabeth Leeds, contendo glossários de termos ligados às favelas e à urbanização, correspondências e estudos não publicados. Esses documentos foram incorporados ao arquivo, no grupo Docência e Pesquisa (ver quadro de arranjo abaixo).

Em 20I4 uma terceira remessa de documentos foi encaminhada e doada pela cientista política à Casa de Oswaldo Cruz. Trata-se de um conjunto de fotografias, negativos e slides, em sua maioria de autoria do titular, objeto de análise em seção específica deste artigo.

\section{A organização do arquivo}

A construção do modelo de arranjo para o arquivo Anthony Leeds teve como referência sua atuação nos períodos em que esteve no Brasil, uma vez que esse foi o contexto de produção dos documentos. Em que pese o grau de subjetividade inerente à constituição de arquivos pessoais, ao analisar os arquivos de cientistas, Santos (2012: 40) afirma que a trajetória profissional e pessoal de um indivíduo encontra-se muitas vezes refletida nos documentos que produz e acumula. A observação desse fato tem justificado a opção pelo método funcional para a construção do quadro de arranjo dos arquivos pessoais pertencentes ao acervo da Casa de Oswaldo Cruz, a partir do qual foi elaborado o quadro de funções e que, por sua vez, representam o primeiro nível de classificação dos documentos. Esses elementos, bem como suas subdivisões, estão discriminados na tabela da página seguinte. 


\begin{tabular}{|c|c|}
\hline Grupo & Subgrupos/dossiês \\
\hline $\begin{array}{l}\text { DP - Docência e Pesquisa } \\
\text { Reúne documentos referentes à atuação de } \\
\text { Anthony Leeds no Programa de Pós-Graduação } \\
\text { em Antropologia do Museu Nacional (UFRJ), bem } \\
\text { como nas Universidades de Columbia e do Texas. } \\
\text { Registra realização de cursos, orientações e } \\
\text { participações em bancas e seminários. A pesquisa } \\
\text { aparece aqui associada à docência, e seus temas } \\
\text { principais recaem sobre as favelas do Rio de } \\
\text { Janeiro em maior número e em outras capitais } \\
\text { brasileiras e latino-americanas. Os principais tipos } \\
\text { documentais são relatórios, artigos, conferências } \\
\text { e comunicações em eventos científicos, } \\
\text { correspondências com outros pesquisadores, } \\
\text { pareceres, monografias, dissertações, teses, } \\
\text { fotografias. }\end{array}$ & $\begin{array}{l}\text { SG - Divulgação de resultados } \\
\text { SG - Intercâmbio científico e cultural } \\
\text { SG - Leitura de interesse profissional } \\
\text { SG - Programação da pesquisa } \\
\text { SG - Registros visuais do trabalho } \\
\text { de campo (I98-) } \\
\text { SG - Registros visuais do trabalho } \\
\text { de campo (I96-) }\end{array}$ \\
\hline $\begin{array}{l}\text { RI - Relações Interinstitucionais e Intergrupos } \\
\text { Reúne documentos referentes à cooperação } \\
\text { técnico-científica nas instituições em que Anthony } \\
\text { Leeds atuou, bem como sua vinculação } \\
\text { a sociedades científicas, participação em grupos de } \\
\text { trabalho e em conselhos científicos. }\end{array}$ & $\begin{array}{l}\text { Dossiê or } \\
\text { Administração Institucional em } \\
\text { Missões Oficiais - Chefe do Programa de } \\
\text { Desenvolvimento Urbano da Organização } \\
\text { dos Estados Americanos } \\
\text { Dossiê o2 } \\
\text { Participação em Comitês - Presidente } \\
\text { do Comitê do Brasil-Estados Unidos, } \\
\text { Movimento de Desenvolvimento e } \\
\text { Organização de Comunidades (Bemdoc) }\end{array}$ \\
\hline $\begin{array}{l}\text { VP - Vida Pessoal } \\
\text { Reúne documentos de identificação, registros } \\
\text { de relações sociais, culturais e associativas de } \\
\text { Anthony Leeds, bem como de sua administração } \\
\text { financeira. }\end{array}$ & $\begin{array}{l}\text { SG - Documentos pessoais } \\
\text { SG - Leituras de interesse pessoal } \\
\text { SG - Organização financeira } \\
\text { SG - Relações de sociabilidade }\end{array}$ \\
\hline
\end{tabular}

As datas-limite dos documentos indicam larga abrangência, situando-se entre I 886 e 1989. No entanto a maioria dos documentos se concentra no final da década de I940 a I960 e de I980, que correspondem aos períodos em que o antropólogo esteve no Brasil e em outros países da América Latina. 
1036

\section{0 arquivo fotográfico: registro de trabalho de campo nas favelas do Brasil}

A história da chegada das fotografias de Leeds à Casa de Oswaldo Cruz tem início anos após o recebimento de seu papelório, em 2007. Em 2014 parte de seu arquivo fotográfico é doado à Casa de Oswaldo Cruz por Elizabeth Leeds. O material fotográfico que chega ao Brasil é um conjunto de 792 ampliações fotográficas em papel (em preto e branco), com negativos correspondentes, e 93 I slides coloridos reunidos por Elizabeth Leeds após uma seleção. ${ }^{33}$ Com sua doação as imagens fotográficas vieram agregar ao conjunto inicial informações sobre os aspectos visualmente recortados pela lente de Leeds e de outras pessoas que com ele trabalharam na prática de registro das observações do trabalho de campo realizado sobretudo em favelas cariocas e em outros estados brasileiros nos anos I960. Esse conjunto foi incorporado ao arquivo no grupo Docência e Pesquisa, dividido em dois subgrupos, intitulados Registros visuais de trabalho de campo (I96-) e (I98-) e reunido em dossiês com nomes de favelas e localidades, quando se trata de favelas cariocas, e por países como Colômbia, Peru, Venezuela e Porto Rico.

Do ponto de vista de seu conteúdo, as fotografias em papel se relacionam às pesquisas realizadas por Leeds em favelas, com incidência maior nas que morou (Tuiuti e Jacarezinho). Em menor concentração estão presentes imagens de algumas cidades brasileiras, além de um conjunto de fotos sobre seus estudos em países da América Latina. Os negativos acompanham esse conjunto, todo ele produzido na década de i960. Os slides, por sua vez, se relacionam, em pequena parte, também aos estudos dos anos I960, mas a maior parte registra aspectos de favelas no Rio de Janeiro já na década de I980, quando esteve mais uma vez no país.

Os documentos fotográficos, em sua conexão com o restante do arquivo, mostram a persistente e sistemática produção de registros visuais como um dos recursos utilizados pelo antropólogo na realização de seus estudos e podem ser vistos como partes de um sistema de descrição, inscrição e registro, figurando ao lado de notas, cartas, relatórios de atividades, apontamentos de todo tipo. Uma primeira apreciação das imagens, portanto, deve levar em conta o centro lógico - o produtor do arquivo - como instância significativa para o entendimento da razão de ser dos registros visuais nesse contexto fundador.

Nem todas as imagens foram produzidas por Leeds; ${ }^{34}$ ele contou com amigos e assistentes na produção de registros visuais; algumas foram a ele doadas (essas em menor quantidade). Embora saibamos dessa rede de agentes próximos a ele nos trabalhos e na captação de imagens, são Leeds e os objetivos de seu trabalho que informam a necessidade e oportunidade da captação dessas cenas.

Ao trabalhar na organização de um arquivo de imagens é importante observar e identificar possíveis padrões na materialidade das fotografias. Esses padrões, ou sua ausência, são aspectos importantes para a compreensão dos sentidos da coleção ou arquivo e do que podem trazer de indícios sobre as pessoas envolvidas em sua produção, bem como sobre os usos pretéritos da documenta- 
ção. No que diz respeito à documentação fotográfica do arquivo de Leeds notamos que há um padrão profissional na produção das ampliações em papel, todas na dimensão I 8 x $24 \mathrm{~cm}$ e monocromáticas. 35 Outro padrão está presente no extenso conjunto de slides, em sua maioria coloridos, montados em molduras plásticas - o que indica seu uso em projetores. Em relação ao primeiro padrão nos indagamos se o fato de ser ele próprio fotógrafo contribuiu para o melhor acabamento e a maior ampliação visando obter condições de observação de detalhes no registro. Já o segundo padrão está associado à projeção e ao compartilhamento das imagens para análise e debate em grupo, o que se coaduna com as informações que temos sobre os usos didáticos que fazia das fotos em seus cursos. Portanto é razoável supor que o antropólogo tenha se dedicado a gerir os formatos desses registros, produzindo seus contornos materiais.

Outra característica que fortalece a hipótese dessa centralização de usos e gerenciamento das fotografias diz respeito às inscrições registradas nos versos de praticamente todas as ampliações em papel. Leeds inscrevia observações que sugerem iniciativas de identificação das imagens, mas também de usos - muitos futuros, como a sua reprodução em slides para aulas. Esses usos posteriores podem fazer supor uma reciclagem das imagens para novos contextos, como o didático. Um exemplo interessante é a inscrição NB em muitos versos. Elisabeth Leeds esclarece que essas iniciais significam a expressão "Note Bem", reforçando o papel reservado ao registro visual - o de captar elementos dignos de nota e de os "arquivar" para miradas futuras com forte sugestão para o que se deve de fato apreciar. ${ }^{36}$

Tanto a dimensão de conteúdo das imagens quanto o aspecto dos padrões que se evidenciam no trato da fotografia como objeto físico poderiam ser submetidos a um exercício de "tipologia" visando dar contornos, ainda que preliminares, aos elementos significativos mais marcadamente presentes nos registros. Esse exercício torna-se possível porque, por meio do arquivo, temos a oportunidade de observar esses documentos em sua dimensão serial. Aspecto típico dos arquivos fotográficos, as fotografias produzidas e acumuladas em série nos permitem acionar formas de leitura em sequência ou por comparação, operações de produção de sentido que podem contribuir para uma abordagem mais crítica em relação à imagem fotográfica como portadora de uma "verdade".

A relação de limites entre as favelas e a cidade parece ser um aspecto visualmente digno de nota, pois é recurso discursivo frequente no conjunto. As várias maneiras de viver nas favelas e as relações de sociabilidade entre seus habitantes parecem também ter sido um ponto explorado visualmente. Os esforços conjuntos para melhorias na comunidade gerando os "mutirões" também foram registrados por Leeds de forma generosa, assim como aspectos de soluções que exemplificam a "economia" própria desenvolvida nesses espaços, responsáveis pela sustentação das formas de ali se viver.

E quais os padrões mais usados por Leeds para abordar fotograficamente esses conteúdos? Também nesse aspecto do que podemos chamar de discur- 
1038

so fotográfico, a análise serial nos sugere interessantes recursos. O conjunto está repleto de tomadas de cena gerais nas quais o que se pretende é menos mostrar um aspecto preciso da realidade retratada do que fornecer informações que se conjugam na cena. Assim, a relação das favelas com a cidade pode ser captada nessas tomadas mais gerais, observando-se, aliás, tentativas de produzir fotos panorâmicas. Um exemplo é a tomada da favela em relação a um cenário urbano de pano de fundo. Segundo Elizabeth Leeds, a intenção era mostrar que as construções seguiam o movimento da passagem do trem.

As tomadas médias, embora ainda mantenham uma abordagem mais amplificada, enfocam, no entanto, um aspecto específico. Esse é o caso de fotografias que mostram conjunto de casas numa rua, a relação de construção das casas numa situação de terreno inclinado, como é o padrão da maioria dos morros cariocas (as construções constituíam atividade econômica importante nas favelas), as soluções usadas pelos moradores na "urbanização" de sua região de morada e os esforços na construção de casas. Ao lado desse tipo de registro, encontramos também muitos retratos, de moradores sobretudo. Há também cenas de conjuntos de pessoas com tomada bem próxima, meio corpo ou corpo inteiro. São grupos que se encontram num bar (ou "birosca", como se lê no verso de algumas fotos), crianças brincando, mulheres carregando baldes de água na cabeça, momentos de eleição de associação de moradores. Nesses casos, a ampliação também se dá fotograficamente, com a cena sendo captada em corpo inteiro, envolvendo o evento e seus agentes na ação que se passa na cena fotografada. Fora do elemento humano, as cenas que apontam aspectos de vida em comunidade próprios da favela são captadas também, quase como "retratos": cartazes de propaganda de serviços, cartazes de propaganda eleitoral, soluções de arquitetura etc. É com essa gama de aspectos que Leeds constrói seu discurso documental.

A relação de Leeds com a fotografia e o audiovisual, assim como com a poesia, foi analisada por Sieber (I994) como um movimento de conjugação de "múltiplas epistemologias" visando coletar informações e ampliar conhecimento no seu ofício de antropólogo. Com relação ao seu envolvimento com a documentação audiovisual - na forma de produção e exibição de fotos e slides show - Leeds concebia a fotografia como "both documentary and expressive" (Sieber, I994: 23), registro com sentidos nascidos da interpenetração das formas estética e documental. Sieber (I994: 23) destaca:

Art, he believed, helps to reveal culture more fully, rather than to obfuscate documentation of culture. He argues against understanding vision - as well as photography - "as objective, somehow 'external' to our feeling, thinking, knowing selves. It is itself immediately immersed in meanings - meanings rooted in our feelingthought-knowledge".

A riqueza de detalhes, de caminhos possíveis de inteligibilidade dessas imagens nos sugere que elas hoje expressam, sem muito nos explicar, a visão de Leeds sobre o fenômeno social que analisava, as escolhas feitas pelo antropólogo 
diante de tantos aspectos visualmente importantes, tornando alguns dignos de nota e de certa forma cristalizados na materialidade fotográfica, que aglutina tempo e espaço no congelamento do instante. No arquivo Leeds, e segundo sua experiência singular, temos um modo de ver as favelas. As visões sobre as favelas nunca foram monolíticas; ao contrário, possuem sua própria historicidade e dinâmica. Assim, o arquivo Leeds em geral e suas imagens em particular nos inspiram, hoje, como fontes para estudos sobre modos de ver as favelas na interseção das "múltiplas epistemologias" acionadas pelo antropólogo no seu trabalho de campo.

Em seus estudos urbanos Leeds construiu uma coleção fotográfica densa e coesa. Tanto a produção quanto a guarda e utilizações das fotografias pelo antropólogo sugerem a relevância da imagem como instrumento de coleta de dados, notadamente visuais, nos trabalhos de campo. Poderíamos supor que elas tiveram lugar na orquestração metodológica que deu origem ao livro A sociologia do Brasil urbano, embora não tenham sido empregadas na sua primeira edição. ${ }^{37}$ Sua ausência, no entanto, não impede que nos indaguemos sobre o papel que tiveram na análise empreendida por Leeds, uma vez que foram instrumentos de registo da realidade por ele analisada. Enfatizamos então o fato de que o conjunto de fotografias proveniente do período de pesquisas empreendidas por Leeds nas favelas cariocas ajuda a refletir sobre a própria natureza do exercício antropológico.

Recebido em 2/6/20I8 | Revisto em 9/9/20I8 | Aprovado em I 2/9/20I8

Licia do Prado Valladares é doutora em sociologia pela Université Toulouse I, fundadora do Urbandata, banco de dados sobre o Brasil urbano, e atualmente é professora emérita da Université Lille I, na França. É autora de vários livros, entre os quais A invenção da favela (2005).

Aline Lopes de Lacerda é doutora em história social pela Universidade de São Paulo, pesquisadora do Departamento de Arquivo e Documentação da Casa de Oswaldo Cruz/Fiocruz e especialista no tratamento arquivístico de documentos fotográficos de valor permanente.

Ana Luce Girão é doutora em história das ciências pelo Programa de PósGraduação em História das Ciências e da Saúde da Casa de Oswaldo Cruz/ Fiocruz, pesquisadora do Departamento de Arquivo e Documentação da mesma instituição, e seus trabalhos enfocam a história das instituições científicas, os arquivos de cientistas e a preservação de acervos das ciências e da saúde. 


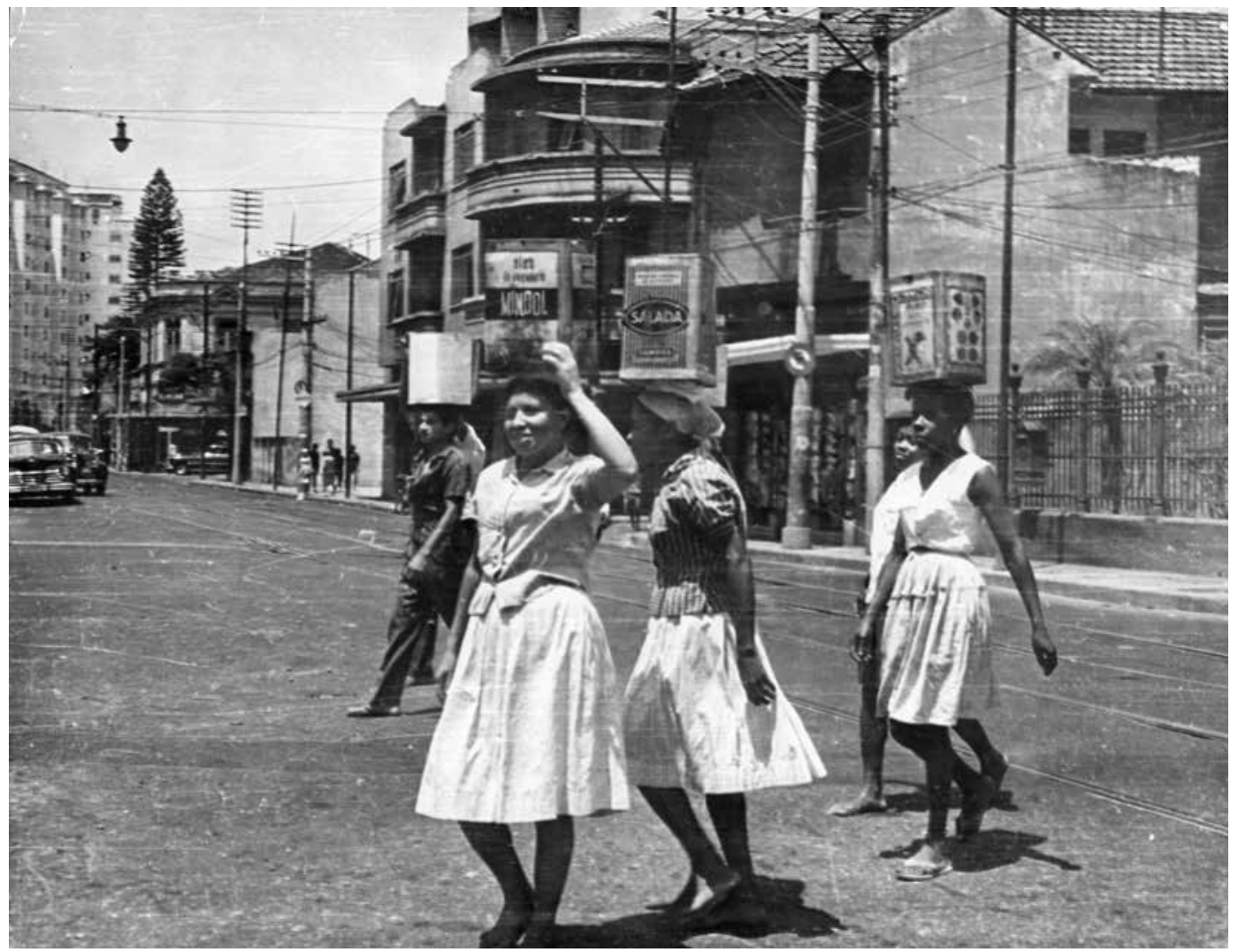

Favela Macedo Sobrinho, I964

Mulheres carregando água

Foto de Cristina Schroeder Barbosa

Todas as fotos são do acervo

Casa de Oswaldo Cruz/Fiocruz

Fundo Anthony Leeds

Digitalização:

Vinícius Pequeno e Roberto Jesus Oscar 
REGISTRO DE PESQUiSA | LICIA DO PRADO VALLADARES | ALINE LOPES DE LACERDA E ANA LUCE GIRÃO

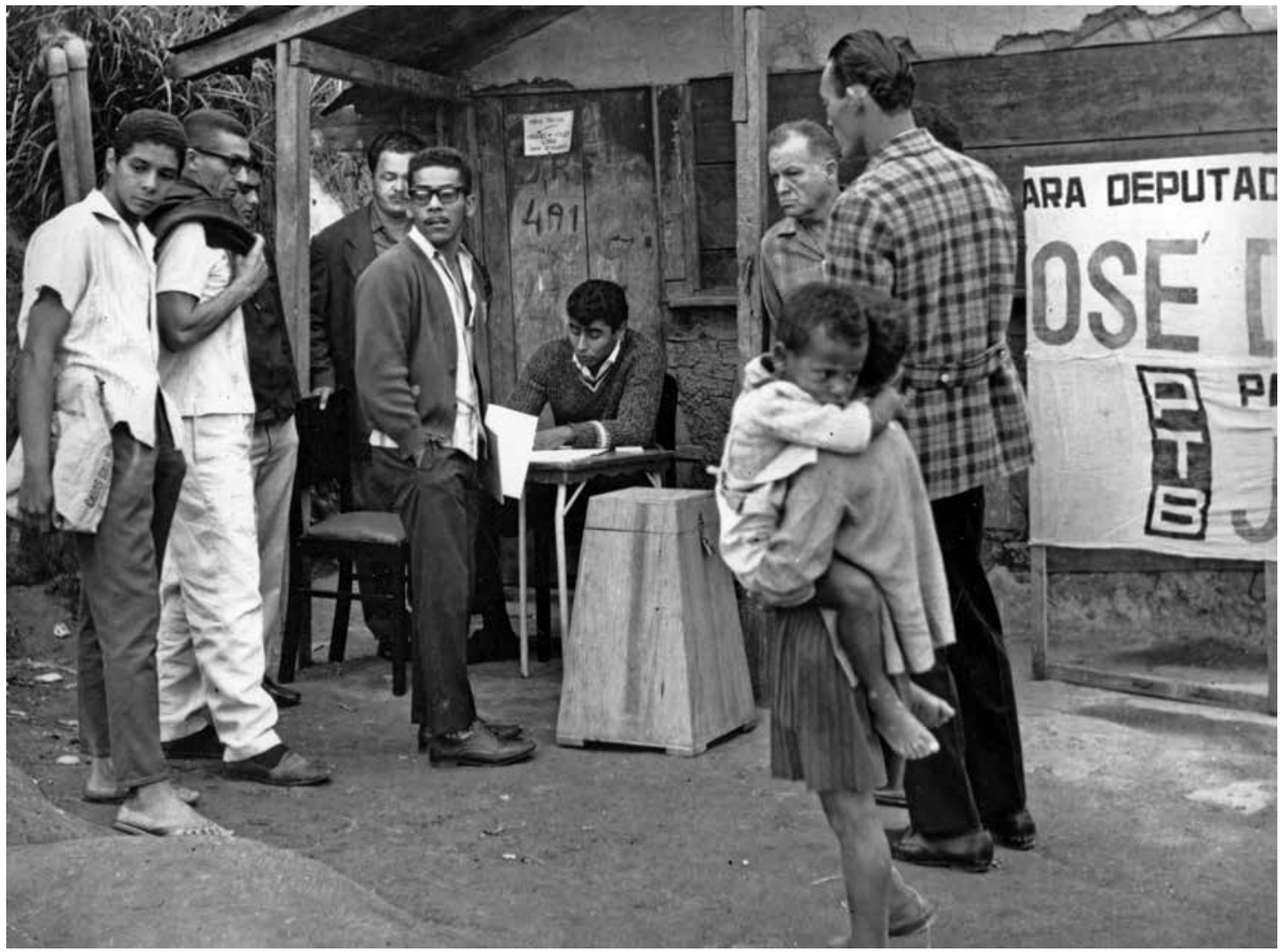




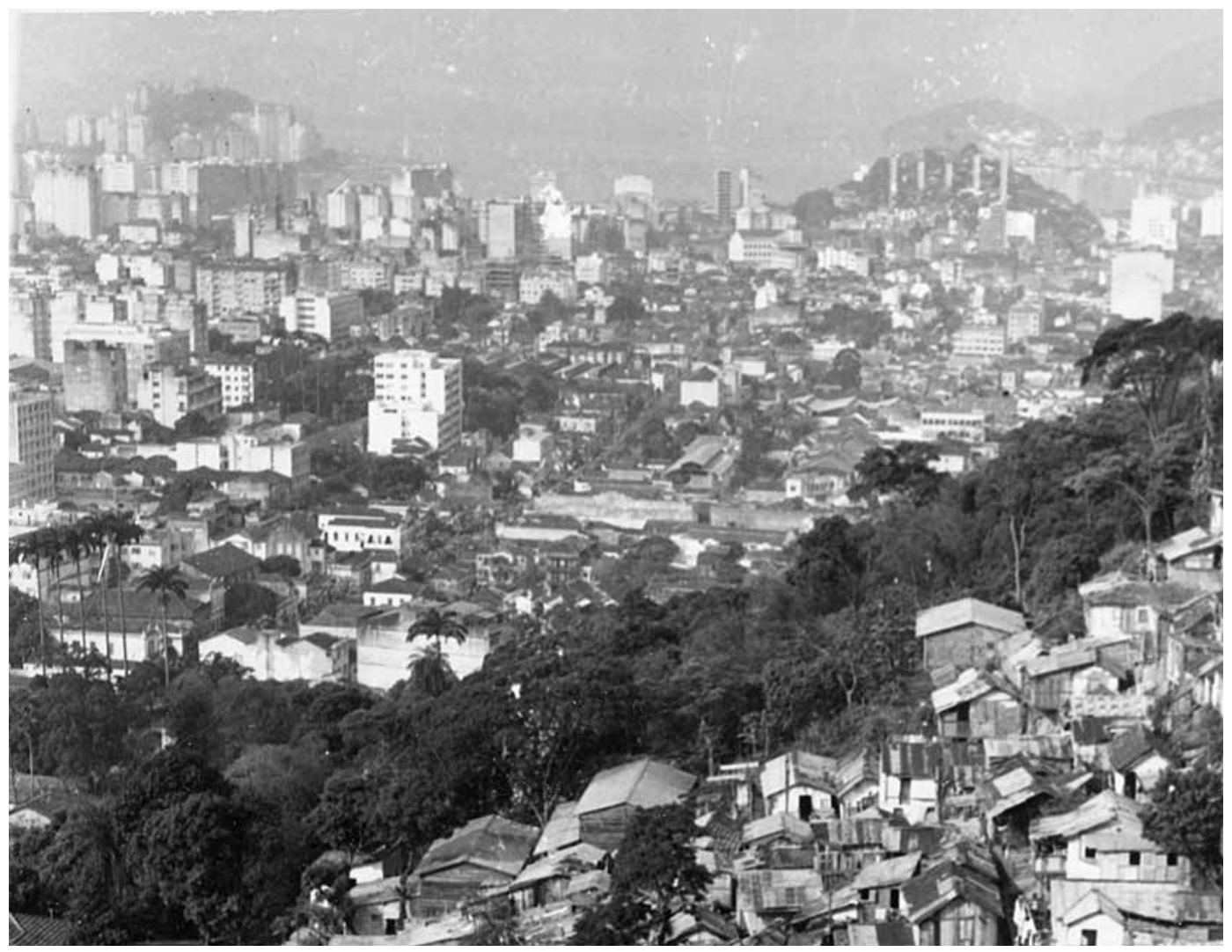

3

Favela Macedo Sobrinho, 1964

Paisagem do Rio de Janeiro com o Pão

de Açúcar ao fundo

Foto de Cristina Schroeder 
REGISTRO DE PESQUiSA | LICIA DO PRADO VALLADARES | ALINE LOPES DE LACERDA E ANA LUCE GIRÃO

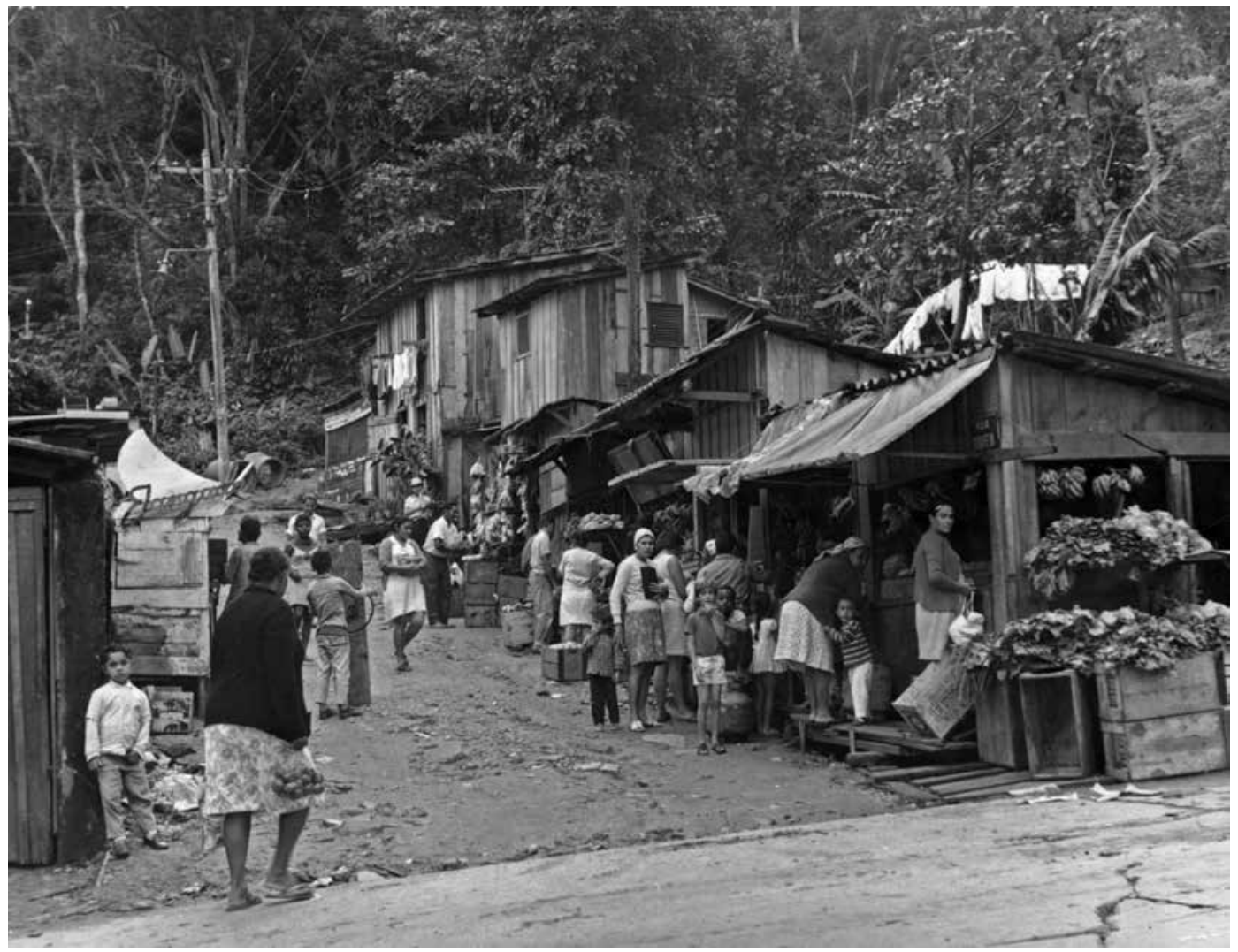


I044

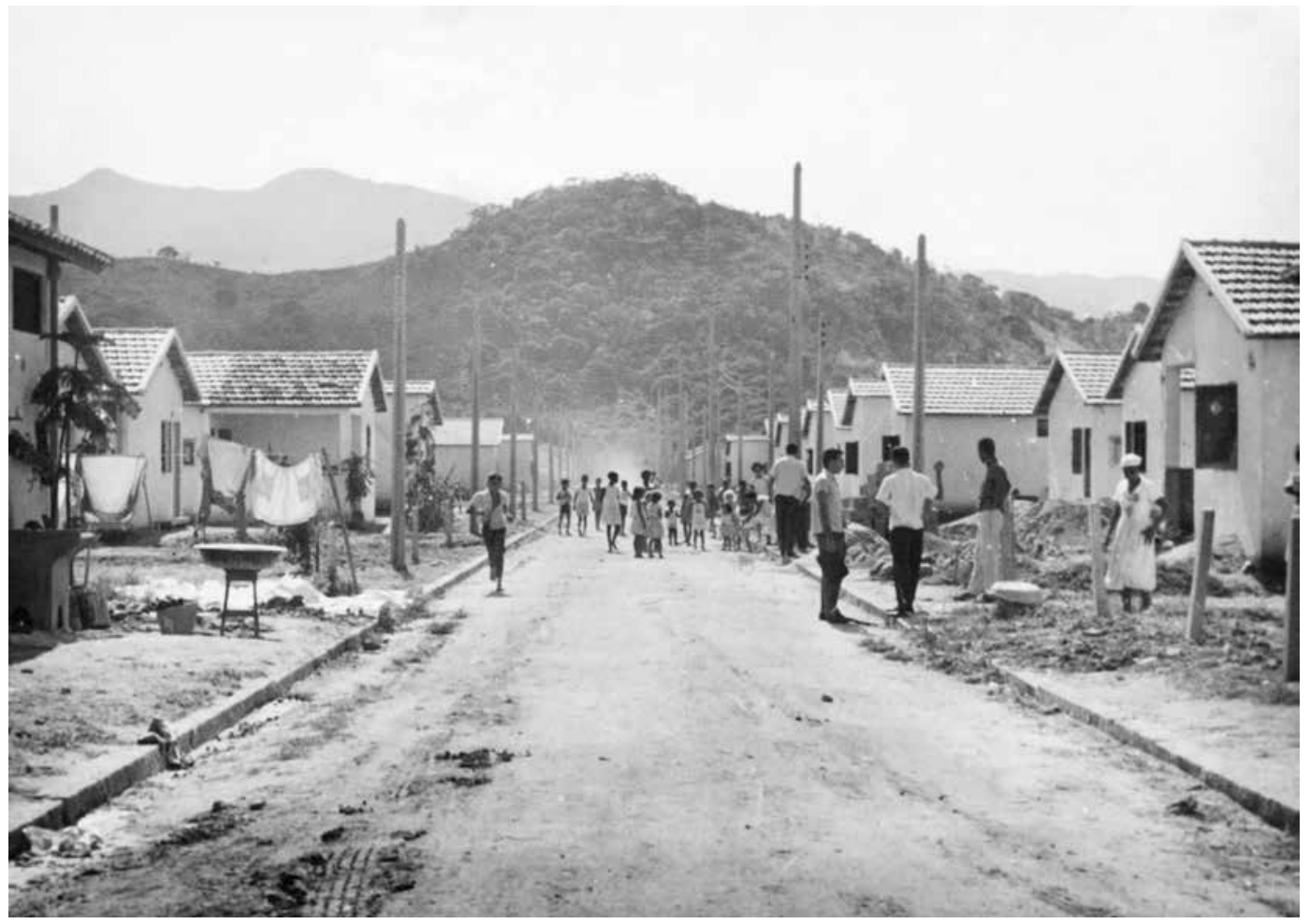


REGISTRO DE PESQUiSA | LICIA DO PRADO VALLADARES | ALINE LOPES DE LACERDA E ANA LUCE GIRÃO

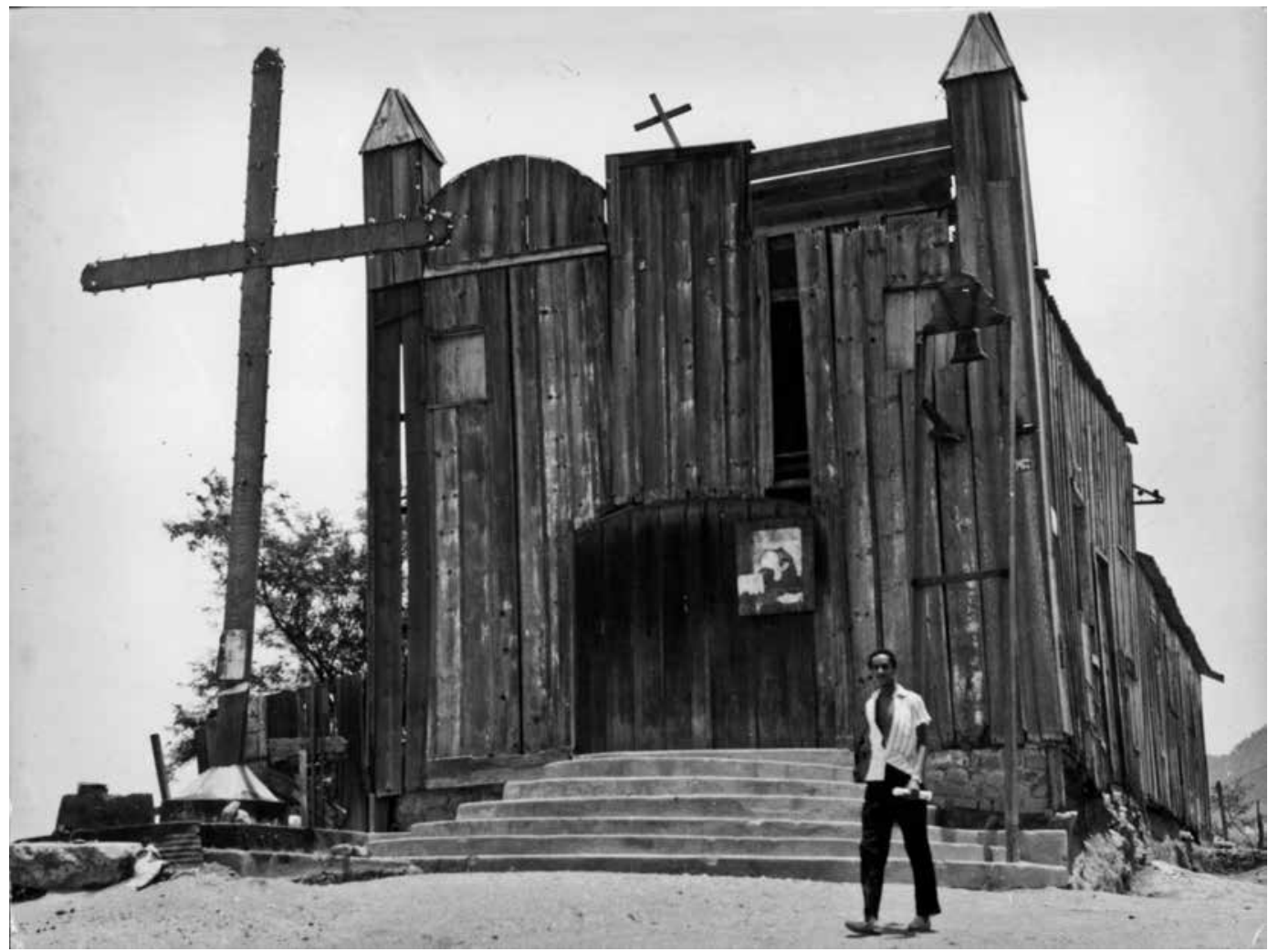


I046

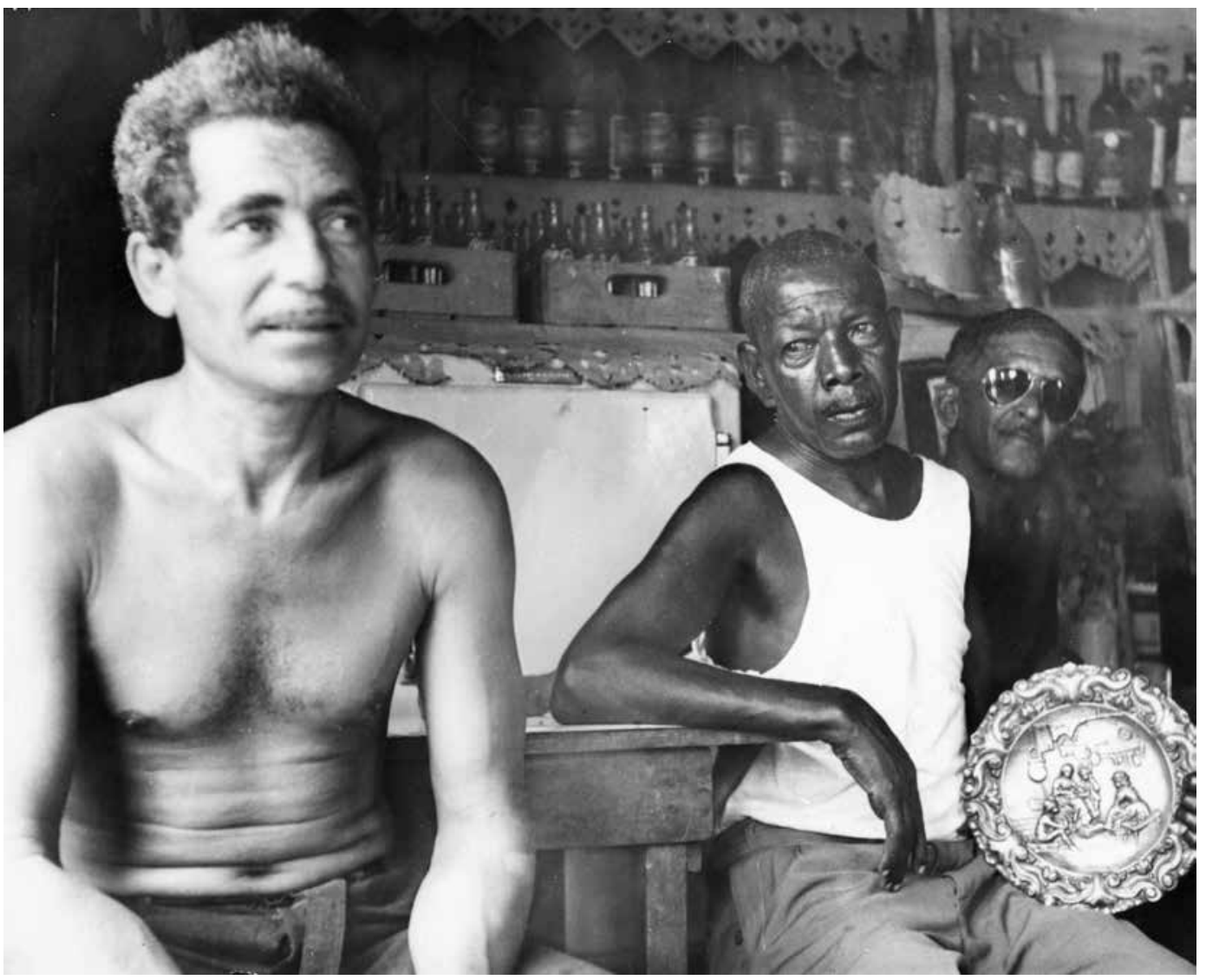


REGISTRO DE PESQUiSA | LICIA DO PRADO VALLADARES | ALINE LOPES DE LACERDA E ANA LUCE GIRÃO

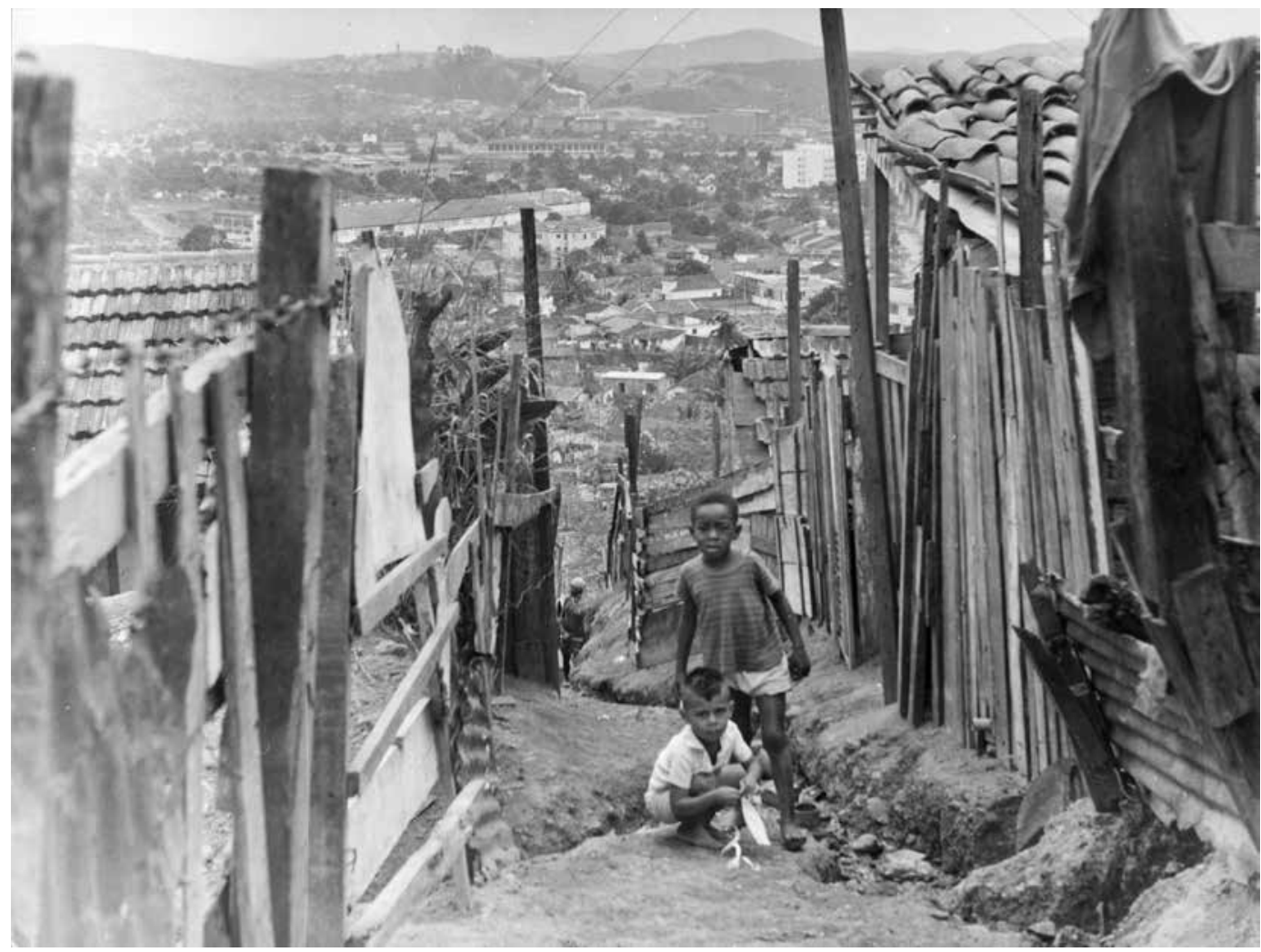


I048

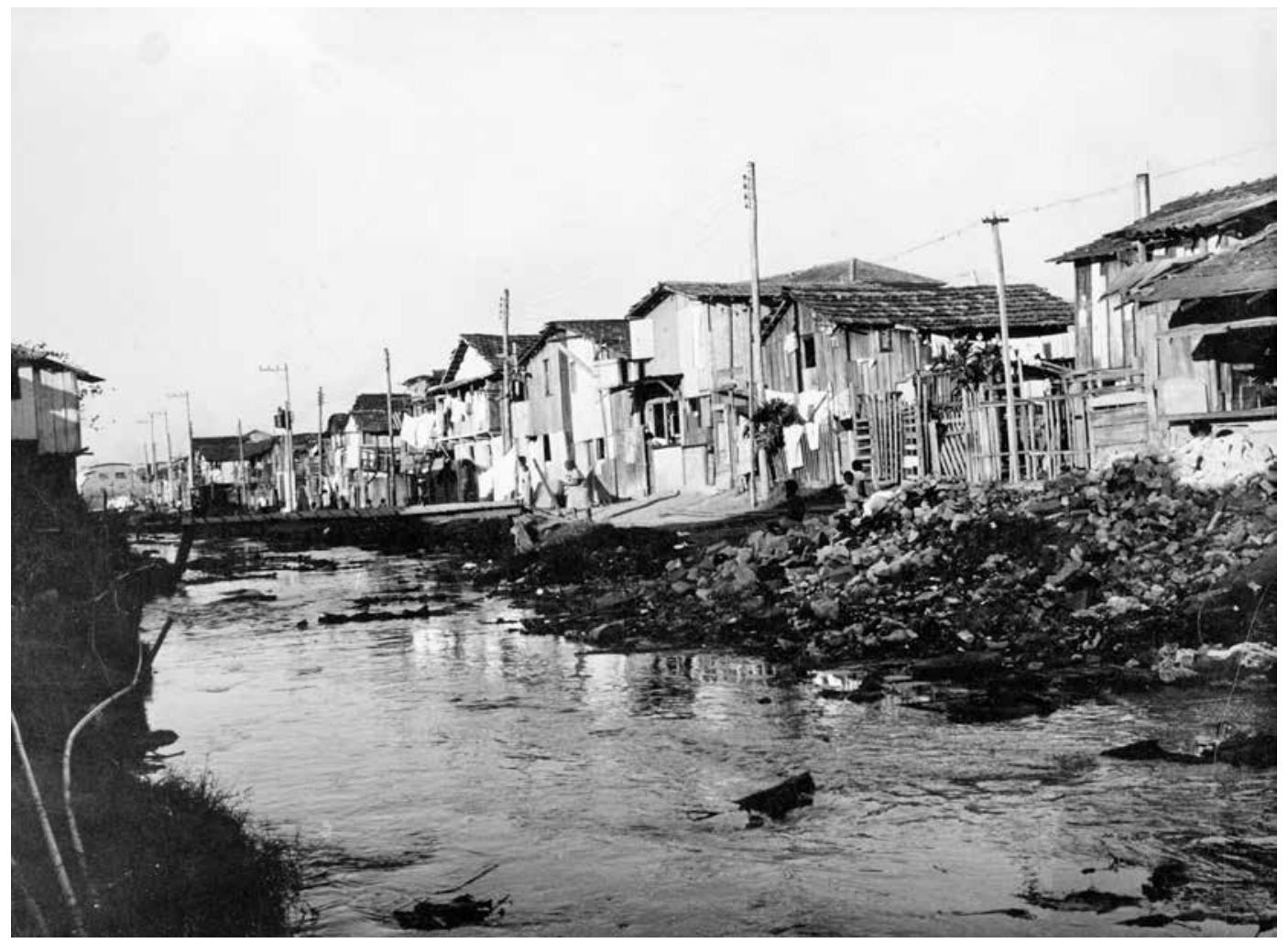


REGISTRO DE PESQUiSA | LICIA DO PRADO VALLADARES | ALINE LOPES DE LACERDA E ANA LUCE GIRÃO

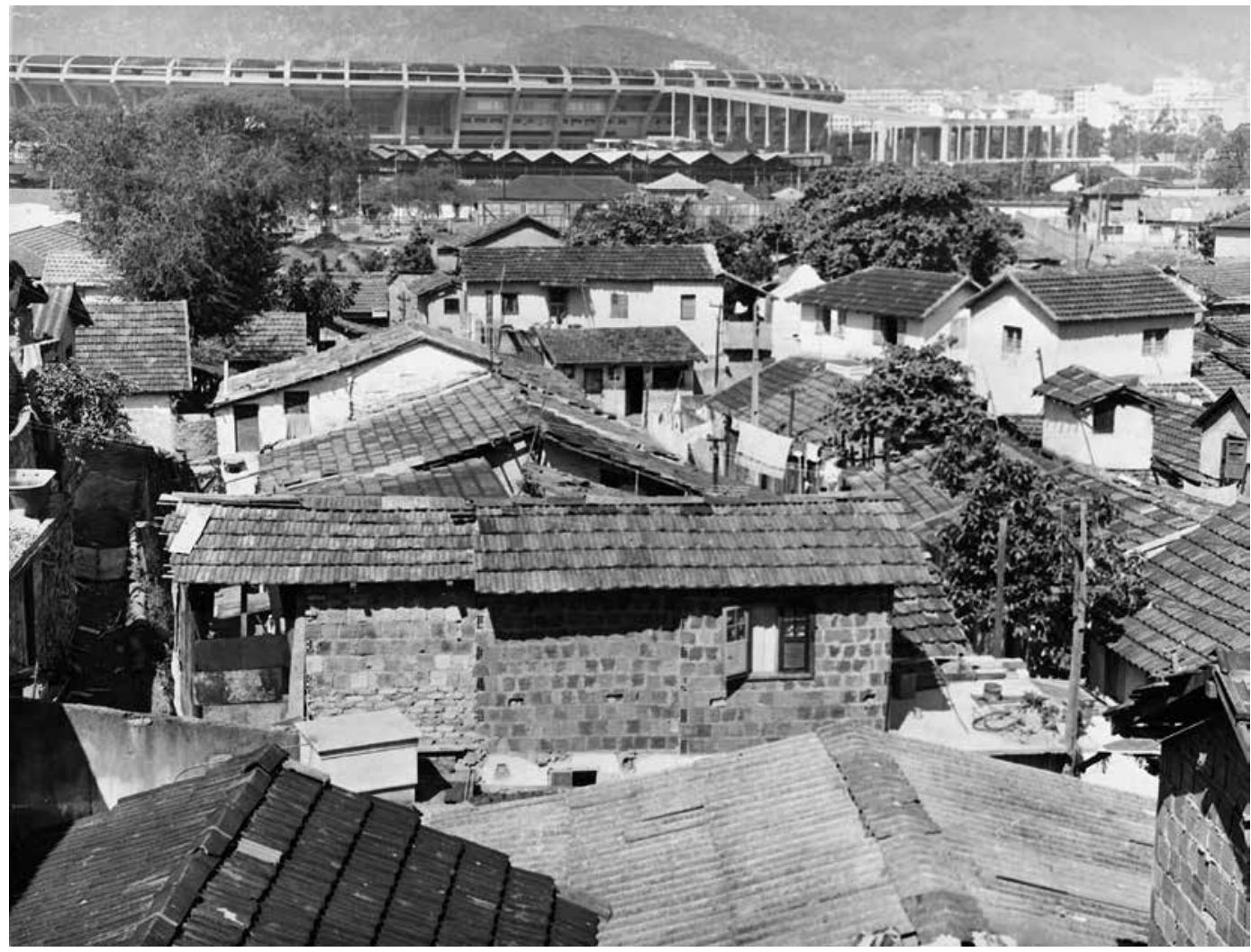


I050

\section{NOTAS}

I O registro de pesquisa abre-se com depoimento de Licia do Prado Valladares sobre a importância e o esquecimento de Anthony Leeds, segundo a autora, que conviveu com o antropólogo norte-americano e assume-se marcada por suas ideias. Tal depoimento foi feito durante o seminário "O Rio que se queria negar: as favelas do Rio de Janeiro no acervo de Anthony Leeds na década de I960", realizado nos dias 22 e 23 de setembro de 2017 no Museu da República, no Rio de Janeiro, quando então também se celebrava a constituição Fundo Anthony Leeds. As responsáveis por esse trabalho arquivístico, Aline Lopes de Lacerda e Ana Luce Girão, nos apresentam no texto que se segue ao depoimento, o plano geral do arquivo. Lidos juntos, os textos cobrem um quadro básico de informações que certamente poderão inspirar novas pesquisas, o que, felizmente, poderá ajudar a ampliar sua recepção e, assim, tornar sua obra menos esquecida entre nós. [N.E.]

2 Gilberto Velho (I945-20I2), antropólogo brasileiro, foi professor do Museu Nacional-UFRJ, dedicado aos estudos urbanos.

3 Yvonne Maggie, antropóloga brasileira, foi professora do Instituto de Filosofia e Ciências Sociais da UFRJ.

4 Luiz Antonio Machado da Silva, antropólogo brasileiro, é professor do Instituto de Estudos Sociais e Políticos da Uerj.

5 Paul Silberstein foi voluntário do Peace Corps Volunteers e posteriormente dedicou-se ao mestrado em antropologia pelo Museu Nacional entre I969 e I97I. Dentre seus trabalhos destacam-se: "Social aspects of odd jobbing in Rio de Janeiro" (I970), seminário em antropologia urbana, apresentado ao Museu Nacional, (datilografado); e "Favela living: personal solution to larger problems" (I969), América Latina, I 2/3.

6 Leeds, Anthony \& Leeds, Elizabeth. (2015). A sociologia do Brasil urbano. 2 ed. Organizada por Elizabeth Leeds e Nísia Trindade Lima. Rio de Janeiro: Editora Fiocruz.

7 Charles Wagley (I9I3-I99I), antropólogo americano, foi professor da Universidade de Columbia e um dos coordenadores da série de estudos de comunidade realizada no 
estado da Bahia, junto com Thales de Azevedo e Luiz de Aguiar da Costa Pinto.

8 Thales de Azevedo (I904-I995), médico baiano que, a partir da década de 1940, se dedicou à antropologia, tendo sido professor de antropologia e etnologia na Faculdade de Filosofia da Universidade de Bahia e, no início da década de I970, na Universidade de Columbia.

9 O programa de desenvolvimento urbano era realizado dentro do Departamento de Relações Sociais, então a cargo do antropólogo mexicano Angel Palerm. Entre as ações desse programa estavam o fomento a programas de pósgraduações em estudos urbanos na América Latina e a pesquisas urbanas nas universidades e centros de pesquisa da região, em parceria com a Organização dos Estados Americanos. Anthony Leeds atuou no programa entre 196I e ig63.

Io Leeds, Anthony. (2015) [1964]. Carreiras brasileiras e estrutura social. Um estudo de caso e um modelo. In: Leeds, Anthony \& Leeds, Elizabeth. A sociologia do Brasil urbano. 2 ed. Organizada por Elizabeth Leeds e Nísia Trindade Lima. Rio de Janeiro: Fiocruz. Originalmente, esse trabalho foi apresentado em I6 de outubro de ig62 para a Sociedade Antropológica de Washington, DC. Também foi publicado em I964 na revista American Anthropologist, 66/6, p. I32 I-I347.

I I José Arthur Rios (I92I-20I7), bacharel em direito e em ciências sociais, foi professor de sociologia de diversas universidades brasileiras e estrangeiras, bem como um dos coordenadores da primeira pesquisa sociológica realizada nas favelas do Rio de Janeiro, "Aspectos Humanos das Favelas Cariocas”, pela SAGMACS - Sociedade de Análises Gráficas e Mecanográficas Aplicadas aos Complexos Sociais.

I2 Padre Lebret (I897-I966), economista e padre dominicano, foi fundador do movimento Economie et Humanisme, da Societé pour l'Application du Graphisme et de la Mécanographie à l'Analyse (Sagma), na França, e da Sagmacs, no Brasil.

I3 Pesquisa encomendada pelo jornal O Estado de São Paulo, que contratou o escritório da Sagmacs para sua realização. A pesquisa foi divulgada em dois suplementos especiais do jornal, em abril de ig6o. 
I052

I4 John F. C. Turner, arquiteto inglês, dedicou-se ao estudo da habitação de baixa renda no Peru. Entre as publicações mais destacadas estão: "Dwelling resources in South America: urbanization case study in Peru" (1963), Architectural Design, London, p. 360-393 (em colaboração com W. Mangin); A new view of the housing déficit (I966), San Juan Seminar Paper, Social Science research Centre, University of Puerto Rico; "The squatter settlement: an architecture that works" (I968), Architectural Design, 38 (Architecture of democracy), p. 354360; Housing by people: towards autonomy in building environments (1976), New York: Pantheon Books; "Uncontrolled urban settlement: problems and policies" (I966), trabalho para o United Interregional Seminar on Development Policies and Planning in relation to urbazination, Pittsburgh.

I5 William Mangin (I923-20I7), antropólogo norte-americano, foi diretor do Peace Corps Volunteers no Peru. Entre as publicações mais destacadas estão: "Latin American squatter settlements: a problem and a solution" (I967), Latin American Research Review, 2/3, p. 64-98; "Squatter settlements" (I967), Scientific American, 217/4, p. 2I-29.

I6 José Matos Mar (I92I-20I5), antropólogo peruano, dedicou-se ao estudo das barriadas de Lima, entre outros temas. Em seus trabalhos, estão: "Migration and urbanization: the barriada of Lima - an example of integration in urban life" (I962). In: P. Hauser (org.), Urbanization in Latin America, New York: Unesco, p. I70-I89; "Consideraciones sobre la situación social del Perú" (I964), América Latina, 7/I, p. 57-70.

I7 A expressão squatter settlements ou assentamentos não controlados foi usada por Leeds como melhor tradução para a língua inglesa do fenômeno favela, comumente traduzido como slums.

I8 A versão original é: "Cocaine and parallel polities in the Brazilian urban periphery: constraints on local level democratization", Latin American Research Review (1996), 31/33, p. 47-83.

I9 Leeds, Anthony \& Leeds, Elizabeth. (I970). Brazil and the myth of urban rurality: urban experience, work and values in statements of Rio de Janeiro and Lima. In: Arthur J. Field (org), City and country in the third world: issues in the modernization of Latin America, Schenkman Pub. Co., p. 229$272,277-285$. 
20 Leeds, Anthony. (I969). "The significant variables determining the character of squatter settlements". América Latina, I2/3, p. 44-86

2I Silberstein, Paul. (I969). "Favela living: personal solution to larger problems". América Latina, I2/3.

22 Oscar Lewis (I9I4-I970), antropólogo norte-americano, destacado pela elaboração da teoria da cultura da pobreza na década de I960, a partir de seus estudos no México.

23 Carolina Maria de Jesus (I9I4-I977), escritora brasileira e moradora de uma favela em São Paulo.

24 Os capítulos da obra A sociologia do Brasil urbano são artigos publicados entre 1962 e 1976 em revistas americanas e redigidas originalmente em inglês.

25 Perlman, Janice. (1979). The myth of marginality, urban poverty and politics in Rio de Janeiro. Berkeley: University of California Press.

26 Robert Redfield (I897-I958), antropólogo norte-americano que se dedicou ao estudo de comunidades camponesas no México. É um dos nomes mais importantes da antropologia de seu país, compondo a primeira geração da Escola de Chicago.

27 No artigo "Favela é comunidade?", Patricia Birman (2008: I13) aborda essa questão, argumentando que o termo comunidade corresponde a um jogo identitário que se contrapõe ao uso dos termos favela e, sobretudo, favelado, "uma das designações mais segregadoras de uso corrente na cidade".

28 Roberto Cardoso de Oliveira (I928-2006), antropólogo brasileiro, foi professor do Museu Nacional, tendo iniciado sua carreira no antigo Serviço de Proteção ao Índio, atuando com Darcy Ribeiro e Eduardo Galvão.

29 Lawrence F. Salmen, norte-americano doutor em antropologia, cujos trabalhos de campo no Rio de Janeiro visavam ao estudo das casas de cômodos e os conjuntos habitacionais para ao quais os moradores das favelas eram removidos, sobretudo na Zona Oeste da cidade. Atualmente, trabalha para o Banco Mundial. Tem entre seus trabalhos, The casas de comodo of Rio de Janeiro: a study of the occupations and accomodations or inner-city slims and a comparison of their chacarteristics with favela (I97I). Ann Arbor: 
I054

university microfilms; e "A perspective on the resettlement of squatters in Brazil" (I969), America Latina, I2/I, p. 73-95. Entre os livros publicados, estão: Reducing poverty: an institutional perspective (1992). Washington: World Bank (Poverty and Social Politic Series Paper, I).

30 Robert Park (I864-I944), antropólogo norte-americano, responsável pela criação do Departamento de Antropologia da Universidade de Chicago e pela consolidação de uma tradição de pesquisa, sobretudo dedicada ao fenômeno urbano, nomeada Escola de Chicago.

3I Anthony Leeds papers, I946-I989. Disponível em <https:// siris-archives.si.edu/ipac20/ipac.jsp? session $=\mathrm{I}_{53} \mathrm{O}_{5} \mathrm{O}_{3} \mathrm{~S} 7$ 443F.6IoI 4 \& profile $=$ all \& source $=\sim$ ! siarchives $\&$ view $=$ subs criptionsummary\&uri $=$ full $=3$ I000o $\sim$ ! 87935 !o \& ri $=\mathrm{I} \&$ as pect $=$ subtabi $57 \&$ menu $=$ search $\&$ ipp $=20 \&$ spp $=20 \&$ staffon $\mathrm{ly}=\&$ term $=$ Anthony+Leeds $\&$ index $=. G W \&$ uindex $=\&$ aspec $\mathrm{t}=$ subtabi57\&menu=search\&ri=I $>$. Acesso em junho de 2018.

32 Outro aspecto também observado foi a presença de conjuntos documentais cujas datas-limite estendiam-se até meados dos anos I990, sendo, portanto, posteriores ao falecimento de Anthony, ocorrido em 1989. Isto indica que houve continuidade na acumulação de documentos. Liz Leeds, ainda em pleno exercício de suas atividades acadêmicas e trabalhando com outros temas além daqueles desenvolvidos com o marido, inseriu, no conjunto inicial novos documentos produzidos e acumulados por ela e referentes ao tema dos direitos humanos. Diante de tal fato, a equipe optou por tratar este conjunto separadamente, criando-se assim o fundo Elizabeth Leeds, distinto do de Anthony Leeds.

33 Atualmente todo o arquivo encontra-se disponível na base de descrição arquivística da COC, Base Arch.

34 Algumas imagens são de autoria de Elizabeth Leeds, e boa parte das fotos sobre a favela Macedo Sobrinho é de autoria da freira Cristina Schroeder, que era ligada à Pontifícia Universidade Católica do Rio de Janeiro e desenvolvia um trabalho social naquela favela. Não foi possível identificar a autoria das demais imagens que não têm a assinatura de Anthony Leeds. 
35 Esse é um padrão de produção de ampliações em papel mais "profissional" na comparação, por exemplo, com a maioria das ampliações "amadoras" do período, realizadas pelo comércio de revelação fotográfica normalmente nos formatos-padrão $9 \times 12 \mathrm{~cm}$ e $10 \times 15 \mathrm{~cm}$, coloridas.

36 A identificação das fotografias contou com o apoio de Elizabeth Leeds que, por sua participação no momento em que esses registros foram produzidos e pelo conhecimento sobre os motivos para essa produção, pôde elucidar muitos aspectos tanto de conteúdo das imagens como de contexto da pesquisa na qual elas se originaram.

37 Por ocasião da organização da segunda edição do livro, em 20I5, e já contando com o arquivo fotográfico, essa "relação latente" das fotos com o livro foi "revelada" finalmente na opção dos organizadores em incluir um caderno de imagens e também na escolha de fotografias que abririam cada um dos sete capítulos. Como indícios dessa conexão, destacamos dois exemplos: na abertura do capítulo 2, intitulado "Poder local em relação com instituições de poder supralocal”, a imagem escolhida refere-se às eleições para a Fafeg na favela Macedo Sobrinho. Já para o capítulo 4, "O Brasil e o mito da ruralidade urbana", a opção recaiu na imagem de uma feira livre na favela da Rocinha.

\section{REFERÊNCIAS BIBLIOGRÁFICAS}

Birman, Patricia. (2008). Favela é comunidade? In: Silva, Luiz Antonio Machado da (org.). Vida sob cerco: violência e rotina nas favelas do Rio de Janeiro. Rio de Janeiro: Nova Fronteira.

Goldstein, Donna M. (2003). Laughter out of place: race, class, violence and sexuality in a Rio Shantytown. Berkeley: University of California Press. (California series in public anthropology, 9).

Heymann, Luciana. (20I2). O lugar do arquivo: a construção do legado de Darcy Ribeiro. Rio de Janeiro: Contra Capa/ Faperj.

Jesus, Carolina Maria de. (I960). Quarto de despejo: diário de uma favelada. São Paulo: Francisco Alves. 
I056

Leeds, Anthony. (2015) [1964]. Carreiras brasileiras e estrutura social. Um estudo de caso e um modelo. In: Leeds, Anthony \& Leeds, Elizabeth. A sociologia do Brasil urbano. 2. ed. Organizada por Elizabeth Leeds e Nísia Trindade Lima. Rio de Janeiro: Fiocruz.

Leeds, Anthony. (I969). The significant variables determining the character of squatter settlements. América Latina, I2/3, p. 44-86.

Leeds, Anthony \& Leeds, Elizabeth. (2015). A sociologia do Brasil urbano. 2. ed. Organizada por Elizabeth Leeds e Nísia Trindade Lima. Rio de Janeiro: Editora Fiocruz.

Leeds, Anthony \& Leeds, Elizabeth. (I970). Brazil and the myth of urban rurality: urban experience, work and values in statements of Rio de Janeiro and Lima. In: Field, Arthur J. (ed.). City and country in the third world: issues in the modernization of Latin America. Cambridge, MA: Schenkman Pub. Co., p. 229-272; p. 277-285.

Leeds, Elizabeth. (I998). Cocaína e poderes paralelos na periferia urbana brasileira. Ameaças à democratização em nível local. In: Zaluar, Alba \& Alvito, Marco (org.). Um século de favela. Rio de Janeiro: FGV.

Maio, Marcos Chor. (1997). A história do projeto Unesco: estudos raciais e ciências sociais no Brasil. Tese de Doutorado em Ciência Política. Instituto Universitário de Pesquisas do Rio de Janeiro.

Mangin, William. (1967). Latin American squatter settlements: a problem and a solution. Latin American Research Review, 2/3, p. 64-98.

Perlman, Janice E. (I977). O mito da marginalidade: favelas e política no Rio de Janeiro. São Paulo: Paz e Terra.

Santos, Paulo R. Elian dos. (2012). Arquivo pessoal, ciência e saúde pública: o arquivo de Rostan Soares entre o laboratório, o campo e o gabinete. In: Silva, Maria Celina Soares \& Santos, Paulo R. Elian dos. (orgs.). Arquivos pessoais: história, preservação e memória da ciência. Rio de Janeiro: Associação dos Arquivistas Brasileiros.

Sheriff, Robin, E. (200I) Dreaming equality: color, race and racism in urban Brazil. New Brunswick/New Jersey: Rutgers University Press. 
Sieber, Timothy. (1994). The life of Anthony Leeds: unity in diversity. In: Leeds, Anthony. Cities, classes and the social order. Edited by Roger Sanjek. Ithaca: Cornell University Press.

Silberstein, Paul. (1969). Favela living: personal solution to larger problems. América Latina, I2/3, p. I83-200.

Turner, J. (I966). Uncontrolled urban settlement: problems and policies. Trabalho apresentado no United Interregional Seminar on Development Policies and Planning in Relation to Urbanization, Pittsburgh.

Velho, Gilberto (20II). Antropologia urbana: interdisciplinaridade e fronteiras do conhecimento. Mana - estudos de antropologia social, Rio de Janeiro, I7/I.

Velho, Gilberto. (1973). A utopia urbana: um estudo de antropologia social. Rio de Janeiro: Zahar.

Wagley, Charles; Costa Pinto, Luiz de Aguiar \& Azevedo, Thales de. (I950). Uma pesquisa sobre a vida social no Estado da Bahia. Salvador: Museu do Estado da Bahia (Publicações do Museu do Estado da Bahia, II).

Zaluar, Alba \& Alvito, Marco (org.). (I998). Um século de favela. Rio de janeiro: FGV. 
1058

\section{ANTHONY LEEDS: O ESQUECIMENTO E A MEMÓRIA}

\section{Resumo}

O texto acopla o testemunho em forma de artigo de Licia do Prado Valladares - uma das principais estudiosas da questão urbana e das favelas no Brasil - sobre a importância da obra de Anthony Leeds, não obstante seu esquecimento pelas novas gerações de pesquisadores, depoimento dado por ocasião da celebração da constituição do Fundo Anthony Leeds, sob a guarda da Casa de Oswaldo Cruz/ Fiocruz; e a nota técnica elaborada por Aline Lopes de Lacerda e Ana Luce Girão sobre o plano geral do arquivo e seu processo de constituição, acompanhada de fotografias, que, de acordo com as organizadoras do acervo, traduzem a riqueza de sua abordagem ao atribuir aos moradores, com os quais interagia em suas pesquisas, a condição de sujeitos ativos na coprodução da favela e da cidade.

\section{ANTHONY LEEDS: FORGETTING AND MEMORY}

Abstract

This section presents two texts. First is the article by Licia do Prado Valladares - one of the leading scholars on the urban issue and favelas in Brazil - testifying to the importance of Anthony Leeds's work, despite its forgetting by new generations of researchers. This testimony was given at the event celebrating the creation of the Anthony Leeds Archive under the safeguarding of Casa de Oswaldo Cruz/ Fiocruz. Second is the technical note produced by Aline Lopes de Lacerda and Ana Luce Girão on the general plan of the archive and how it was assembled, accompanied by photographs that, according to the organizers of the collection, translation the richness of his approach in taking the residents with whom he interacted in his research as active subjects in the coproduction of the favela and the city.
Palavras-chave

Arquivo Anthony Leeds; antropologia urbana; questão urbana;

favelas; cidades.

\section{Keywords}

Anthony Leeds Archive; Urban Anthropology; urban issue; favelas; cities. 